NBER WORKING PAPER SERIES

\author{
FINITE LIFETIMES, BORROWING \\ CONSTRAINTS, AND \\ SHORT-RUN FISCAL POLICY
}

R. Glenn Hubbard

Kenneth L. Judd

Working Paper No. 2158

NATIONAL BUREAU OF ECONOMIC RESEARCH 1050 Massachusetts Avenue

Cambridge, MA 02138

February 1987

This paper was presented at the winter meeting of the Econometric Society, New Orleans, December 1986. We are grateful to Laurence Kotlikoff and Jonathan Skinner for helpful comments. The research reported here is part of the NBER's research program in Financial Markets and Monetary Economics. Any opinions expressed are those of the authors and not those of the National Bureau of Economic Research. 
NBER Working Paper \#2158

February 1987

\section{Finite Lifetimes, Borrowing Constraints, and Short-Run Fiscal Policy}

\section{ABSTRACT}

Recent developments in public finance in the analysis of dynamic government debt policies have emphasized effects on the distribution of real resources across generations. At the same time, macroeconomists have emphasized the importance of the length of the time horizon over which agents optimize their decisions about consumption for judging the effects of fiscal policy on aggregate demand. Much of the discussion of these issues has focused on whether linkages among generations are sufficient to give consumers infinite horizons. To the extent that horizons are finite, debt burdens can be shifted to future generations, and substitutions of debt for taxes have real effects.

This paper argues that, as a matter of quantitative significance, theoretical and empirical emphasis on the importance of finite horizons for the analysis of many fiscal policies is misplaced. Studies of the role of finite horizons in determining the effects of short-run fiscal policies on consumption have been conducted largely under the assumption of perfect capital markets. We show that while the marginal propensity to consume (MPC) out of temporary tax changes is nonzero in finitehorizon models, it is not very large. We demonstrate that the MPC is, however, quite sensitive to the importance of restrictions on borrowing in the economy. The clear implication is that shifting emphas is from the length of the planning horizon to the structure of capital markets is an important step for empirical research.

R. Glenn Hubbard

Department of Economics Northwestern University Evanston, I11inois 60201 (312) 491-8224
Renneth L. Judd Hoover Institution Stanford Unt versity Stanford, California 94305 (415) 723-9175 


\section{INTRODUCTION}

Recent developments in public finance in the analysis of dynamic government debt policies have emphasized effects on the distribution of real resources across generations (Kotlikoff, 1984; Auerbach and Kotlikoff, 1987; Hubbard and Judd, 1986). At the same time, macroeconomists have emphasized the importance of the length of the time horizon over which agents optimize their decisions about consumption for judging the effects of fiscal policy on aggregate demand (Blanchard, 1985). Much of the discussion of these issues has focused on whether linkages among generations are sufficient to give consumers infinite horizons (see the discussion in Barro, 1974, 1978; Tobin, 1980; and Feldstein, 1982). To the extent that horizons are finite, debt burdens can be shifted to future generations, and substitutions of debt for taxes have real effects (Modigliani, 1961; Diamond, 1965; Blanchard, 1985).

This paper argues that, as a matter of quantitative significance, theoretical and empirical emphasis on the importance of finite horizons for the analysis of many fiscal policies is misplaced. ${ }^{1}$ Studies of the role of finite horizons in determining the effects of short-run fiscal policies on consumption have been conducted largely under the assumption of perfect capital markets. We show that while the marginal propensity to consume (MPC) out of temporary tax changes is nonzero in finite-horizon models, it is not very large. Poterba and Summers (1986) present evidence that short-term tax reductions and government budget deficits have led to significant reductions in national saving in recent years; such a finding is inconsistent both with Ricardian equivalence and with the predictions of finite-horizon models under perfect capital markets. We demonstrate that the MPC is, however, quite sensitive to the importance of restrictions on borrowing in the economy. The clear implication is that shifting emphasis from the length of the planning 
horizon to the structure of capital markets is an important step for empirical research. ${ }^{2}$

The paper is organized as follows. We put forth an intertemporal optimizing model of consumption emphasizing the role of finite lifetimes in section II. The model allows for a stochastic transition from low earnings to high earnings to facilitate analysis of effections borrowing restrictions on the consumption of individuals with low current wages. We apply the model to examinations of short-run fiscal policy in section III; the marginal propensity to consume out of short-run tax cuts is modeled both in the presence and absence of borrowing constraints. We demonstrate that the estimates of the aggregate MPC depend critically on both the importance of borrowing restrictions and on the distribution of the tax reduction. Some conclusions and implications are discussed in section IV.

\section{FINITE LIFETIMES, BORROWING CONSTRAINTS, AND CONSUMPTION}

To analyze the relative importance of finite horizons and borrowing constraints for the effects of temporary tax changes on consumption, we employ a simple analytical model of an economy in which the number of births is constant each year and each person has a probability p of dying each year. This form of uncertainty about life expectancy is highly stylized and serves only to create a finite-horizon problem, not to calculate age-related marginal propensities to consume per se (as for example in Hubbard, 1986). We capture the essence of a rising lifetime earnings profile by assuming that each person begins work earning a wage of $w_{1}$ and has a probability $q$ each year of experiencing an increase in his wage to $w_{2}$. In the steady state, the share of the labor force in the high-productivity state is $\theta_{2}=q /(p+q)$; the share in the low-productivity state, $\theta_{1}=p /(p+q)$. The total wage income going to 
low-productivity workers equals $\theta_{1} \mathrm{w}_{1}$ per living person, and wage income to high-productivity workers is $\theta_{2} \mathrm{w}_{2}$ per capita.

All agents are assumed to have logarithmic utility functions defined over consumotion. ${ }^{3}$ If $T$ is the time of death, utility is given by

$$
U=E\left\{\int_{0}^{T} e^{-\rho t} \ln c d t\right\}
$$

where $\rho$ is the rate of time preference. This assumption simplifies exposition because logarithmic utility implies that an individual's consumption in each period is proportional to his stocks of human capital and financial assets in perfect capital markets. More specifically, if $h$ is the expected present value of all future wage income and a is financial wealth, then the individual consumption function $c$ is

$$
c=(\rho+p)(h+a)
$$

To determine aggregate consumption, it is necessary to compute the human capital of low and high-productivity workers ( $H_{1}$ and $H_{2}$, respectively). Since a proportion pdt of current high-productivity workers die during the interval $(t, t+d t)$, and the market discounts future wealth at the interest rate $\mathrm{r}, \mathrm{H}_{2}$ obeys

$$
H_{2}(t)=w_{2} \theta_{2} d t+(1-r d t)(1-p d t) H_{2}(t+d t)
$$

This equation states that the current human capital of high-productivity workers equals the current wage flow plus the present value of the expected human capital of the current workers, who are a proportion 1 - pdt of high- 
productivity workers dt units of time in the future. ${ }^{4}$ This can be expressed as the differential equation

$$
\dot{\mathrm{H}}_{2}=-\mathrm{w}_{2} \theta_{2}+(\mathrm{p}+\mathrm{r}) \mathrm{H}_{2} \cdot
$$

To determine $\mathrm{H}_{1}$, we must take into account both deaths and transitions to high productivity. With probability qdt a low-productivity worker becomes high-productivity, and with probability pdt dies. Hence the current lowproductivity workers are $1-(p+q) d t$ of tomorrow's low-productivity workers. The qdt proportion that become high-productivity workers comprise a pdt proportion of all such workers tomorrow, and hence tomorrow will have pdt of $\mathrm{H}_{2}$. Therefore,

$$
\begin{aligned}
H_{1}(t)= & w_{1} \theta_{1} d t+(1-p d t)(1-r d t)\left[(1-q d t) H_{1}(t+d t)\right. \\
& \left.+ \text { pdt } H_{2}(t+d t)\right] .
\end{aligned}
$$

In differential equation form, this becomes

$$
\dot{\mathrm{H}}_{1}=-\mathrm{w}_{1} \theta_{1}+(\mathrm{p}+\mathrm{q}+\mathrm{r}) \mathrm{H}_{1}-\mathrm{pH}_{2} \text {. }
$$

Financial assets per capita a, follow

$$
\dot{a}=\mathrm{ra}+\mathrm{w}_{1} \theta_{1}+\mathrm{w}_{2} \theta_{2}-\theta_{1} \mathrm{c}_{1}-\theta_{2} \mathrm{c}_{2},
$$

where $c_{1}\left(c_{2}\right)$ is the average consumption of low- (high-) productivity workers. The sum $\mathrm{A}+\mathrm{H}_{1}+\mathrm{H}_{2}$ is total wealth of the current population. 
We consider below the determination of aggregate consumption both in the presence and absence of borrowing restrictions. Where capital markets are perfect and there are no restrictions on borrowing, ${ }^{5}$ aggregate consumption $C$ is given by

$$
C=(\rho+p)\left(A+H_{1}+H_{2}\right)
$$

In the steady state of the aggregate economy, $H_{1}, H_{2}$, and $A$ assume the values $\mathrm{H}_{1}^{*}, \mathrm{H}_{2}^{*}$, and $\mathrm{A}^{*}$, respectively, where

$$
\mathrm{H}_{1}^{*}=\left(\frac{p}{p+q}\right)\left(\frac{w_{1}}{p+r}\right)+\left(\frac{q}{p+q}\right)\left(\frac{w_{2}-w_{1}}{p+r}\right)\left(\frac{p}{p+q+r}\right)
$$

$$
H_{2}^{*}=\frac{{ }^{w_{2}}{ }_{2}}{p+r} \text {, and }
$$

$$
A^{*}=\frac{w_{2}(r-\rho)}{(\rho+p+r)(p+r)}+\left(\frac{w_{1}-w_{2}}{\rho+p+r}\right)\left(\frac{p}{p+q}\right)\left(\frac{q+r-\rho}{q+p+r}\right) .
$$

We assume that $r>\rho$, so that $A^{*}>0$. The human capital of high-productivity individuals is obtained by means of a simple present-value calculation. $H_{1}$ is a weighted average of the discounted low-productivity earnings and later high-productivity earnings, adiusted for transition probabilities.

Consider an individual entering the economy with no assets but with the ability to borrow against future earnings. When he starts working, he has his low-productivity human capital $h_{1}$, where

$$
h_{1}=\frac{w_{1}}{p+r}+\left(\frac{w_{2}-w_{1}}{p+r}\right)\left(\frac{q}{p+q+r}\right) .
$$


That is, $h_{1}$ represents the discounted value of receiving $w_{1}$ until death, plus the discounted value of the difference until death between $w_{2}$ and $w_{1}$, times the probability of reaching high productivity, $q /(p+q)$, times the expected discount factor at the time of that transition conditional on having reached high productivity, $(p+q) /(p+q+r)$. The inclusion of the second term in $h_{1}$ is due to the perfect capital market that allows the individual to borrow against the future high-productivity wage stream. Desired consumption in the initial period is

$$
c_{0}=(\rho+p) h_{1}=\frac{\rho+p}{p+r} w_{1}\left[1+\left(\frac{w_{2}}{w_{1}}-1\right)\left(\frac{q}{p+q+r}\right)\right] .
$$

Note that $c_{n}>w_{1}$ if $w_{2}$ is much greater than $w_{1}$, or if $q$ is large relative to $p+r$. Intuitively, initial consumption exceeds the initial wage if the initial wage is much smaller than subsequent wages or if the transition to higher wages is especially rapid.

Many forms of borrowing restrictions are possible; ${ }^{6}$ we analyze the constraint arising from a nonnegativity constraint on assets. In particular, we appeal to transactions costs and bankruptcy laws in explaining credit restrictions. ${ }^{7}$ As we will show, such constraints can influence behavior even when consumption is not restricted by the level of current resources. That is, the anticipation of binding constraints in the future can be important (see also Zeldes, 1986).

If low-wage individuals cannot borrow against future high wages and desired initial consumption exceeds the initial wage, consumption behavior is substantially affected. For the case in which $q$ is high and assets are zero for constrained individuals, we need only examine $\mathrm{H}_{2}^{*}$ and $\mathrm{A}^{*}$ in the aggregate analysis, since consumption equals the wage for all low-productivity workers. Hence 


$$
\dot{\mathrm{H}}_{2}=-\mathrm{w}_{2} \theta_{2}+(\mathrm{p}+\mathrm{r}) \mathrm{H}_{2} \text {, and }
$$

$$
\dot{\mathrm{A}}=\mathrm{w}_{2}{ }_{2}{ }_{2}+\mathrm{rA}-(\rho+\mathrm{p})\left(\mathrm{H}_{2}+\mathrm{A}\right) \text {. }
$$

In the steady state of the constrained system,

$$
\mathrm{H}_{2}^{*}=\frac{\mathrm{w}_{2}{ }_{2}}{\mathrm{p}+\mathrm{r}} \text {, and }
$$

$$
A^{*}=\frac{w_{2} \theta_{2}(r-\rho)}{(\rho+p+r)(p+r)}
$$

As expected, the constrained equilibrium yields a greater steady-state asset level, the increase equaling

$$
\left(\frac{w_{2}-w_{1}}{\rho+p+r}\right)\left(\frac{p}{p+q}\right)\left(\frac{q+r-\rho}{q+r+p}\right)
$$

The difference is larger as the productivity difference and the proportion of liquidity-constrained individuals is greater. The ratio of steady-state asset levels in the constrained and unconstrained cases is

$$
\left(\frac{w_{2}-w_{1}}{\rho+q+r}\right)\left(\frac{p}{q}\right)\left(\frac{q+r-\rho}{q+r+\rho}\right)\left(\frac{p+r}{r-\rho}\right) .
$$

This effect is likely to be quantitatively important. 8

It is important to note that even if individuals are unable to borrow against future earnings, they may still save in the initial low-productivity period. The following analysis determines the nature of paths of consumption and asset accumulation for that case. Since consumption when the highproductivity state is reached will be $(\rho+p)\left[a+w_{2}(p+r)^{-1}\right]$ if assets are 
a, the marginal value of assets at the moment of transition will be $(\rho+p)^{-1}\left[a+w_{2}(p+r)^{-1}\right]^{-1}$, which is $V^{\prime}(a)$ if $V(a)$ is defined to be the value of assets in the high-productivity state. An individual in the lowproductivity state will therefore face the following problem:

$$
\begin{aligned}
& \int_{0}^{\infty} e^{-(p+p+q) t}[\ln c+q V(a)] d t, \text { subject to } \\
& \dot{a}=(r+p) a+w_{1}-c .
\end{aligned}
$$

This problem differs because the budget constraint does not include any insurance payment a worker receives when he fails to move to high productivity. That insurance was implicitly assumed above when we focused on perfect capital markets. Intertemporal arbitrage arguments show that

$$
\dot{c}=-(\dot{p}+q-r) c-\frac{q c^{2}}{(\rho+p)(a+h)}
$$

Phrase diagram analysis of (19) together with the budget constraint in (18) reveals that there are two possible cases -- depending on whether desired initial consumption exceeds the initial wage. Figures 1 and 2 display those cases. In both cases the stationary loci for a and c are

$$
\begin{aligned}
& \dot{a}=0+a=\left(w_{1}-c\right) /(r+p), \text { and } \\
& \dot{c}=0+c=\left(\frac{\rho+q-r}{q}\right)(\rho+p)(a+h) .
\end{aligned}
$$

Let $c_{0}$ be the value of consumption on the $\dot{c}=0$ locus if $a=0$. The critical condition distinguishing the two cases is how $c_{0}$ compares to $w_{1}$. 
FIGURE 1

CONSUMPTION AND ASSETS WHEN $c_{0}>\nabla_{1}$

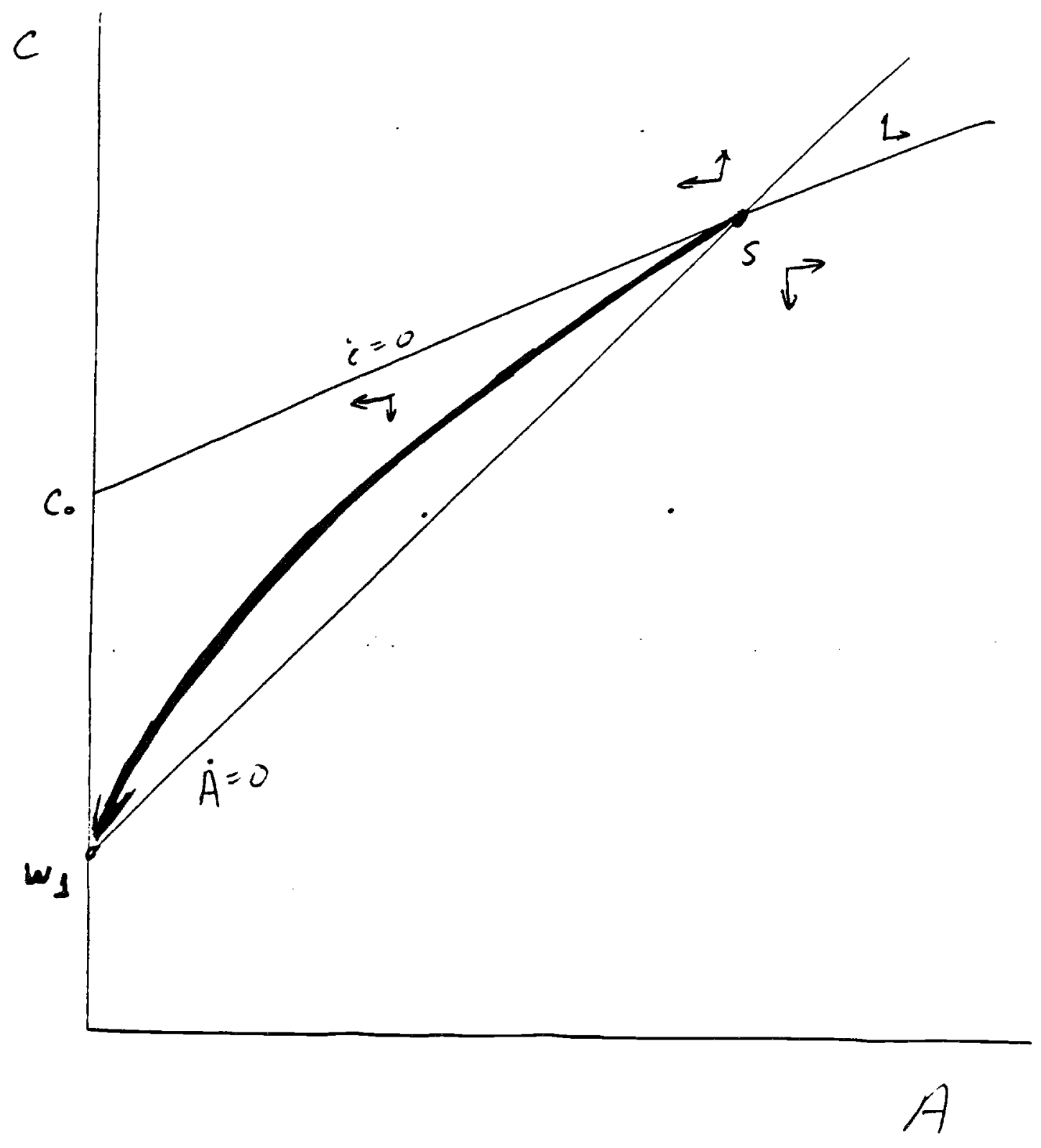


FIGURE 2

CONSUMPTION AND ASSETS WHEN $c_{0}<\nabla_{1}$

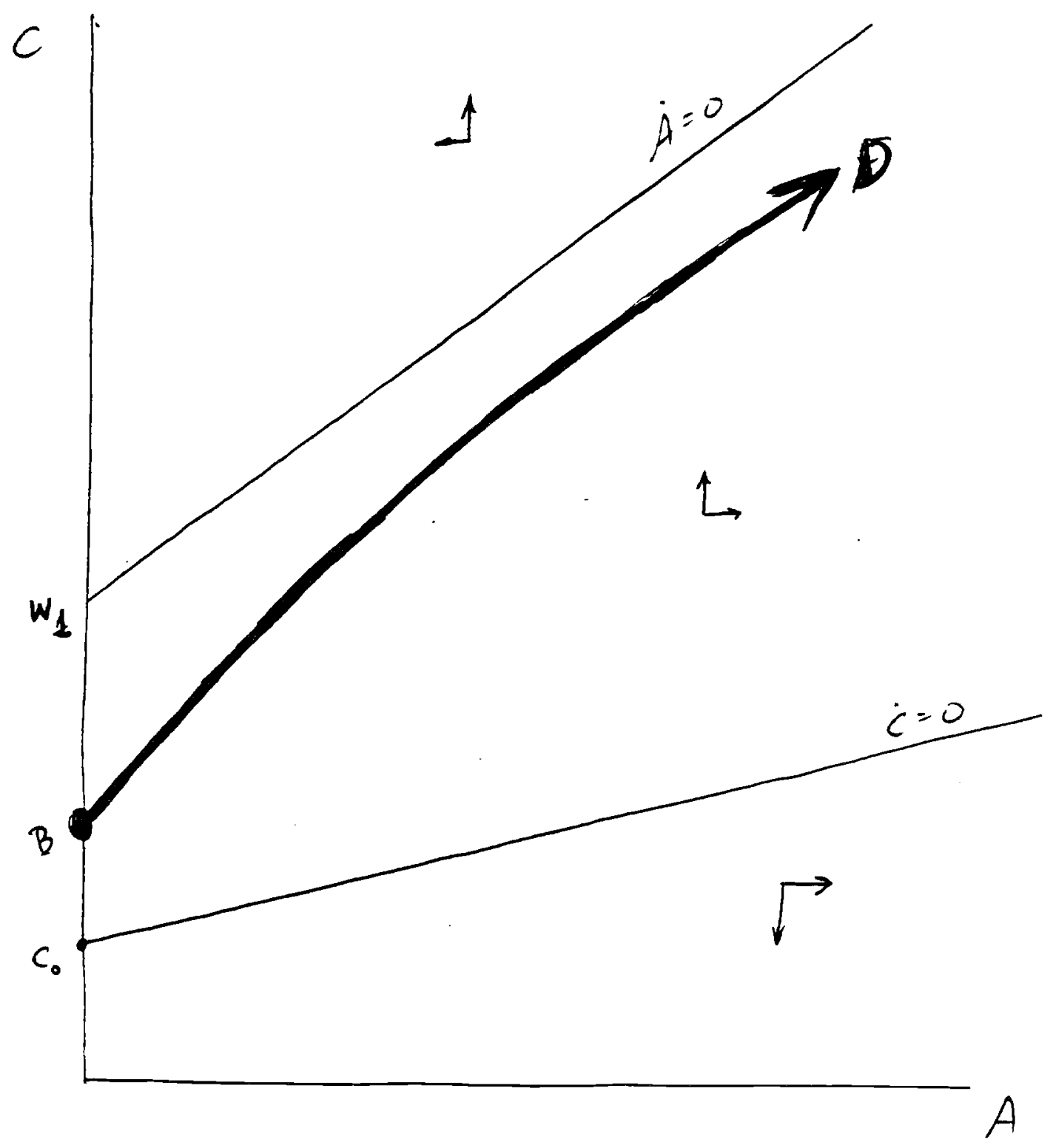


Figure I illustrates the case wherein $c_{0}>w_{1}$. The crucial feature here is that the steady-state level of assets is unstable. Concavity of the problem (18) implies that the optimal policy is continuous in assets. When assets are zero, consumption must be just the wage or less. However, if consumption at $a=0$ were less than $w_{1}$, the phase diagram shows that assets would grow without bound and consumption would fall to zero, a situation which contradicts the transversality condition at infinity. Hence, consumption at $a=0$ is exactly $w_{1}$. This implies that the consumption-asset path is as depicted by the curve $S w_{1}$ in Figure 1. That path is computed by solving for the reverse-time system starting at $c=w_{1}$ and $a=0$.

If, on the other hand, $c_{0}<w_{1}$, Figure 2 obtains. Here, the consumption path is some path, such as BD, which lies between the $\dot{a}=0$ and $\dot{c}=0$ loci. It can be determined by standard shooting methods. The differences between the two cases are intuitive. If the prospective wage increase, $w_{2} / w_{1}$, and its likelihood, q, are high, then the worker would like to consume against the future income, but cannot. Hence, consumption is driven up to its upper bound, $w_{1}$, if he has no assets. This is the case depicted in Figure 1 . In Figure 2, the wage increase is not large or is not likely to occur soon. In this case the borrowing constraint is not as binding and some savings will occur.

Within this setup, we can consider more generally the impact of borrowing restrictions on the marginal propensity to consume out of assets for lowproductivity workers. As before, let $h_{1}$ represent human capital in the lowwage state, $1 . e .$, the present value of future wages. We present in Table 1 simulated marginal propensities to consume out of assets for low-productivity workers (expressed as a ratio to MPCs under perfect capital markets). Four levels of initial assets relative to human capital are considered. Expressing 
TABLE 1

MPCs IN CONSTRAINED REgIME RELATIVE TO PERFECT CAPITAL MARKETS

$A=0.025 \mathrm{~h}_{1}$

\begin{tabular}{c}
\hline \multicolumn{1}{c}{1.5} \\
$\mathrm{w}_{2} / \mathrm{w}_{1} 2^{5}$ \\
$\mathrm{~A}=0.075 \mathrm{~h}_{1}$ \\
\hline
\end{tabular}

$q / p$

4

8

16

32

1.50

2.59

3.29

2.14

3.39

4.48

2.37

4.12

6.21

2.42

4.49

8.17

$\begin{array}{rlrccr} & & 4 & 8 & 16 & 32 \\ \mathrm{w}_{2} / \mathrm{w}_{1} & 1.5 & 1.07 & 1.20 & 1.18 & 1.05 \\ & 5 & 1.58 & 1.88 & 1.93 & 1.65 \\ & 2.22 & 2.84 & 3.56 & 3.78\end{array}$

$A=0.15 \mathrm{~h}_{1}$

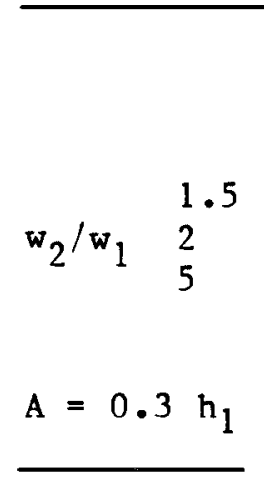

$q / p$

4

1.02

1.24

1.79
8

1.03

1.32

2.11
16

1.01

1.25

2.23
32

1.00

1.07

1.89
4

1.5

2

1.01

1.07

1.45

$q / p$

8

16

32

1.01

1.07

1.53
1.00

1.02

1.38
1.00

1.00

1. 10

Note: In all cases, $r / p=1.25$ by assumption. Entries in the table represent the ratio of the MPC under borrowing constraints to the MPC under perfect capital markets. 
asset positions in this way removes any dependence on the time unit. For each asset parameterization, we consider a set of values for $w_{2} / w_{1}$ (prospective wage increases) and $q / p$ (expressing the ease of transition to the high-wage state). ${ }^{9}$ Again, the interpretation of the entries in Table 1 is such that for upper left entry in the top panel, the MPC out of assets in the constrained regime is 1.5 times as large as in the perfect-capital-market regime.

When we solve for consumption functions, we find that the borrowing constraint does cause a substantial change in behavior. Over the cases we examine, the MPC is increased significantly over reasonable levels of assets. Below we consider the influence of borrowing restrictions on calculations of the effects of short-run tax changes on consumption.

\section{MODELING THE EFFECTS OF TEMPORARY TAX CHANGES ON CONSUMPTION Finite Horizons, Borrowing Constraints, and the Effects of Temporary Tax Changes}

The recent resurgence of arguments for the "Ricardian equivalence" proposition that debt-financed tax cuts should have no effects on consumer spending calls into question whether finite-horizon models ("life-cycle" or otherwise) are adequate representations of decisionmaking about consumption. The basic debate here is an old one. Under the basic version of the lifecycle model with only a lifetime budget constraint, a temporary tax cut followed by an anticipated offsetting tax increase should have no effect on consumer spending. An obvious qualification is that the aggregate marginal propensity to consume out of a temporary tax cut will be positive to the extent that borrowing constraints affect a substantial number of consumers. 10

The effects of temporary tax changes on consumption are easily captured in the model we have outlined. As we emphasize the role of borrowing restrictions here, we concentrate on the income effects of tax policy. 
Suppose that taxes $\tau(t)$ per capita are imposed at time $t$. Viewing such taxes as reductions in the wage shows that the human capital of each current worker at time $t$ is reduced by 11

$$
T(t)=\int_{t}^{\infty} e^{-r(s-t)} e^{-p(s-t)} \tau(s) d s .
$$

As pointed out by Blanchard (1985), debt-financed tax cuts are not neutral even in the presence of perfect capital markets, since a reduction in current taxation financed by higher taxation of future generations stimulates a positive wealth effect for the current generation, causing its consumption to rise. 12

The pure finite-lifetimes effect (that is, under perfect capital markets) of a short-run tax change is quite small, however. Suppose, for example, that $\tau(t)$ is decreased by $d \tau$ during the interval $\left[0, t_{1}\right]$, with a compensating tax increase of $e^{r t} d \tau$ during the interval $\left[t_{2}, t_{1}+t_{2}\right]$. In that case, total human capital net of taxes for individuals at $t=0$ increases by $\left(1-e^{-p t} 2\right)\left(1-e^{-(r+p) t} 1\right)(r+p)^{-1}$. Therefore, the marginal propensity to consume out of a debt-financed tax cut, $m$, is

$$
m=\frac{d C}{d \tau}=(\rho+p)\left(1-e^{-p t} 2\right)\left(\frac{1-e^{-(r+p) t} 1}{r+p}\right)
$$

The marginal propensity to consume out of a tax cut involves the three terms on the right-hand side of the equation. The first, $(\rho+p)$, is the MPC out of increments to wealth. The other two terms comprise the increment to wealth. That increment is greater the longer the tax cut lasts and the longer is the delay before the compensating tax increase occurs. The present value of the tax cut during $\left[0, t_{1}\right]$ is $\left(1-e^{-(r+p) t} 1\right) /(r+p)$. Only $1-e^{-p t} 1$ 
of that is left after expected future taxes are considered. While $(p+p) /(r+p)$ may very well be close to unity, the other terms are substantial only if $p$, $t_{1}$, or $t_{2}$ is large. For example, if $p=0.02, \rho=0.015, r=0.04, t_{1}=5$, and $t_{2}=20$, we are considering a five-year tax cut financed with a twentyyear delay, during which time people die at a rate of 2 percent a year. In this case, the MPC out of a tax cut would be only about 0.05 , even though we postulated an extended tax cut financed with a relatively long delay.

Results in a liquidity-constrained regime are quite different. Consider first the case outlined in Figure 1 where low-productivity workers consume their wage. Then the impact of a tax cut is just

$$
\mathrm{dC}=\theta_{1} \mathrm{~d} \tau_{1}+\theta_{2} \mathrm{~d} \tau_{2}
$$

where $d \tau_{i}$ is the size of the tax cut for workers with wage $w_{i}$. The aggregate MPC out of the tax cut, .

$$
\bar{m}=\frac{\theta_{1} d \tau_{1}+\theta_{2} 2^{m d \tau_{2}}}{\theta_{1} d \tau_{1}+\theta_{2} d \tau_{2}}
$$

will be substantially higher. Suppose $\theta_{1}=0.20$ and $d \tau_{1}=d \tau_{2}$. The aggregate MPC becomes 0.24 , not 0.05 ; that is, the MPC is more than quadrupled by assuming that only twenty percent of the work force is liquidity-constrained. 13 These findings are of particular interest for the debate over tests of neutrality propositions. While finite horizons per se are not likely to be of much significance for analyses of whether fiscal policy changes are neutral with respect to aggregate demand, capital-market imperfections may be quantitatively important in invalidating neutrality propositions. 
Poterba and Summers (1986) show that the large budget deficits of the early 1980s were associated with substantial decreases in private saving, rather than with an increase in private saving, as would be predicted by neutrality propositions. Such a result is consistent with our calculations of the potential importance of liquidity constraints in assessing the effects of deficits on national saving. Two other possibilities here are that consumers are simply myopic, or that it is the non-lump-sum nature of actual taxes that accounts for the failure of Ricardian equivalence.

With respect to the first point, some individuals may be myopic, failing to take into account future fiscal actions implied by current tax policy, or they may be rule-of-thumb consumers, consuming a fixed proportion of disposable income not consistent with the predictions of the life-cycle mode1. However, if myopia rather than borrowing constraints accounted for high MPCs on the part of some individuals, there is little reason to believe that such behavior should be concentrated in particular groups - for example, the young or the poor. Empirical evidence from microdata suggests strongly, however, that it is in particular families with low net worth who display excess sensitivity of consumption to income relative to that predicted by the life-cycle model under perfect capital markets (Runkle, 1984; Hayashi, 1985a; Zeldes, 1985).14

Second, Barsky, Mankiw, and Zeldes (1986) consider the positive MPC arising from the risk-sharing effects of progressive taxation. While the aggregate MPCs out of temporary tax changes calculated here are significantly larger than those under perfect capital markets (and finite horizons), they are generally smaller than those calculated by Barsky, Mankiw, and Zeldes. These variations are traceable to three differences. First, because many of their calculations are performed within a two-period model, their perfect- 
capital-markets MPC is much larger than in our model. Second, while we consider uncertainty regarding the transition to high earnings, earnings uncertainty in Barsky, Mankiw, and Zeldes also encompasses the possibility of future reductions in earnings. Third, Barsky, Mankiw, and Zeldes assume that individuals start with no initial assets, amplifying the need for precautionary saving and the MPC out of short-run tax changes. 15

As noted before, our analysis abstracts from distortionary taxes, concentrating on the income effects of tax policy. Of course, real-world taxes are not lump-sum and involve substitution effects as we11. Ignoring price effects is not likely to bias our examination of the relative unimportance of finite horizons for the analysis of short-run fiscal policy. For individuals who participate in capital markets, the opposing redistribution and distortionary-tax effects modeled in Judd (1986) ${ }^{16}$ act to cancel each other, since they pull consumption in opposite directions. These opposing forces mitigate the impact of finite lifetimes for such consumers. Liquidity-constrained consumers are not affected by changing saving incentives, and will react strongly to net-of-tax income changes.

In summary, liquidity constraints seem the most promising reason accounting for nontrivial marginal propensities to consume out of short-run tax changes.

Returning to the more general case considered before -- where MPCs of liquidity-constrained consumers are not necessarily equal to unity -- we can rewrite the aggregate MPC in (23) as

$$
\bar{m}=\frac{\theta_{1} \gamma \mathrm{md} \tau_{1}+\theta_{2} \mathrm{md} \tau_{2}}{\theta_{1} \mathrm{~d} \tau_{1}+\theta_{2} \mathrm{d \tau} \tau_{2}},
$$


where $\gamma$ corresponds to the ratio of the MPC in the constrained regime to the MPC in the unconstrained regime (calculated for various cases in Table 1).

\section{Effects of the Distribution of Tax Cuts on Consumption}

That MPCs are high for constrained consumers (as in Table 1), with the implication that borrowing constraints are potentially important in assessing the impacts of short-run tax changes on consumption, does not imply that MPCs out of actual tax cuts will be large even if a significant fraction of the population is constrained. As noted in Hubbard and Judd (1986), the formulation of $\bar{m}$ in equation (23) highlights the importance of the distribution of the tax cut relative to the effect arising simply from finite horizons. Letting $B=\mathrm{d} \tau_{2} / \mathrm{d} \tau_{1}$, we can rewrite equation (23) as:

$$
\overline{\mathrm{m}}=\frac{{ }_{1}+\theta_{2} 2^{B m}}{\theta_{1}+\theta_{2} \beta} .
$$

When $d \tau_{1}$ and $d \tau_{2}$ are not equal, liquidity constraints may become less important. For example, if instead of a uniform tax cut, low-income workers enjoy a smaller absolute tax cut than high-income workers do -- both cuts financed separately by later increases in taxes in the same class - then $\bar{m}$ is reduced. Indeed, many changes in proportional or progressive tax systems result in greater relative relief for the high-income group, dampening the effects of borrowing constraints on the aggregate MPC out of a temporary tax cut.

Consider for example a linear tax on earnings of the form

$$
\tau_{i}=t\left(w_{i}-\alpha\right)
$$


where $t$ denotes the (constant) marginal tax rate and $t \alpha$ is the exemption. In such a tax system, $\beta=\left(w_{2}-\alpha\right) /\left(w_{1}-\alpha\right)$. In the proportional tax case, $\beta=w_{2} / w_{1}$.

In Table 2, we illustrate the sensitivity of the aggregate MPC to changes in the distribution of the proceeds of the tax cut -- considering a uniform, lump-sum tax cut (where $d \tau_{1}=d \tau_{2}$ and $\beta=1$ ), a tax cut in a proportional system $\left(\beta=w_{2} / w_{1}\right)$, and a tax cut in a "progressive" system $\left(\beta=\left(w_{2}-\alpha\right) /\left(w_{1}-\alpha\right)\right)$. For all cases, we calculate aggregate MPCs for a tax cut lasting five years to be financed with either a ten-year delay or a twenty-year delay. As before, we assume that $w_{1}=0.7 w_{2}$; in the progressive case, the exemption is calibrated to be half of the earnings of a low-income individual. To preserve comparability with the calculations discussed before, consumers with low earnings $\left(w_{1}\right)$ are assumed to have no initial assets. The MPCs presented in Table 2 show clearly the variation in the effects of tax changes on aggregate demand according to their distributional characteristics. For example, when twenty percent of the population is constrained, the aggregate MPC is reduced by about one-third from 0.24 when the tax cut is uniform to 0.156 when the cut is made in the progressive system defined above.

The dependence of the aggregate MPC on the structure of the tax cut points up clearly the potential problems of using estimates of the effects of temporary tax changes on consumption to make inferences about the significance of liquidity-constrained consumers in the economy. If tax cuts were lump-sum and uniform, econometric evidence on the effects of temporary tax changes on consumption could be used to infer the importance of liquidity-constrained consumers in the determination of aggregate consumption. However, even holding constant the underlying fraction of the population with constrained consumption, MPCs will vary substantially with respect to lump-sum, 
TABLE 2

\section{SIMULATED AGgRegate MARgIKAL PROPENSITY TO CONSURER OUT OP A TBAPORARY TAX CUT}

Fraction of Population Liquidity-Constrained ${ }^{b}$

Ten-Year Delay

$$
0
$$

10

20

25
Lump-Sun Tax Cut $^{C}$
Tax Cut in Proportional Systend
Tax Cut in Progres81ve Systeme

$$
\begin{array}{r}
2.7 \% \\
12.4 \\
22.2 \\
27.0
\end{array}
$$

$2.7 \%$

8.8

14.5

17.5
$2.7 \%$

7.8

13.5

16.6

Twenty-Year Delay

0
10
20
25

$$
\begin{array}{r}
5.0 \% \\
14.5 \\
24.0 \\
28.8
\end{array}
$$

$5.0 \%$

10.0

15.6

18.6

Notes: aThe aggregate marginal propensity to consume is calculated for a five-year tax cut financed by a ten-year delay or a twenty-year delay.

bequa1 to $\theta_{1}$.

$c_{\text {That is, }} d \tau_{1}=d \tau_{2}$.

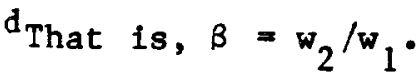

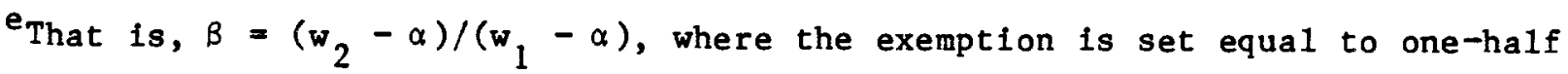
of the earnings of an individual in the low-wage state. 
proportional, and progressive tax reductions. In particular, to the extent that many previous actual policy experiments involved temporary changes in nonlinear tax systems, their effects on consumption would be small even in the presence of a substantial number of liquidity-constrained consumers. This result is likely to be important in future empirical tests of Ricardian equivalence.

\section{CONCLUSIONS AND IMPLICATIONS}

The issue of whether government budget deficits affect aggregate demand lies at the center of debates over Ricardian equivalence in public finance and macroeconomics. In particular, the length of the planning horizon over which individual consumption decisions are made has been a major focus of discussion. We use a simple finite-lifetime model to examine the relative importance of capital-market imperfections (borrowing restrictions) and finite horizons in analyzing Ricardian-neutrality propositions. While the model is stylized, it captures most essential features required to consider these issues. The findings are clear: Pure intergenerational wealth redistribution effects, the focus of standard finite-life analyses, are in general small. The theoretical analysis of short-run policy effectiveness arguments is more affected by borrowing constraints than by considerations of finite lifetimes. The kinds of tax policy experiments offered in practice, however, do not permit inferences about the importance of constraints in determining aggregate MPCs.

Our findings of small short-run effects of government deficits in finitehorizon models under perfect capital markets do not, of course, imply that the effects of deficits on the capital stock in the long run will be small (see for example Auerbach and Kotlikoff, 1987). We believe, however, that 
arguments about the relative unimportance of finite horizons relative to imperfections in capital markets for analyzing effects of fiscal policy changes on consumption can be extended beyond short-run policy exercises. Just as ignoring capital-market imperfections can lead to an underestimate of the MPC out of temporary tax changes, the opposite can be true for permanent intergenerational transfers facilitated by fiscal policy. For example, the transfers accompanying the introduction of the social security system were large and long-lasting (Feldstein, 1974; Hurd and Shoven, 1983), leading to large predicted effects on consumption. Social security retirement annuities are financed on a pay-as-you-go basis by a payroll tax, so that receipts collected from the working population are used to pay benefits to retirees. Explicit borrowing against future social security benefits is not permitted, and when borrowing restrictions are important, liquidity constraints on young workers are exacerbated by the payroll tax. The predictions for large increases in consumption based on a finite-horizon model with perfect capital markets are likely to be incorrect (Hubbard and Judd, 1985). 


\section{Notes}

1 Poterba and Summers (1986) offer an empirical criticism of the application of finite-horizon models to the analysis of Ricardian equivalence, noting that wartime debt in the U.S. has historically been paid off sufficiently rapidly as to avoid shifting debt burdens to future generations.

2 Barsky, Mankiw, and Zeldes (1986) also emphasize a capital-market imperfection in this context, arising from individual's ability to insure against (individual-specific) earnings uncertainty.

3 For a discussion of the effects of borrowing restrictions on consumption in more general finite-horizon (life-cycle) models with more general specifications of preferences, see Hubbard and Judd (1986).

${ }^{4}$ This appeals to the assumption that the population is in a steady state in which the number of transitions from low to high productivity equals the deaths of high-productivity workers.

${ }^{5}$ We mean "perfect capital markets" to imply the ability both to borrow against future earnings and to insure against a delayed transition into high

productivity and long life. For the purposes of this analysis, we assume the existence of markets for annuities.

${ }^{6}$ Empirical evidence in support of the excess sensitivity of consumption to changes in disposable income can be found in Hall and Mishkin (1982), Hayashi $(1982,1985 a)$, Flavin (1984), and Zeldes (1985).

${ }^{7}$ The source of borrowing restrictions can be important. Hayashi (1985b) discusses conditions under which excess sensitivity traceable to borrowing constraints from imperfect information in the credit market is not exploitable by stabilization policy. The form of borrowing restrictions we stress will be exploitable. In addition, the sort of collateral restrictions on loans to borrowers under asymmetric information discussed in Calomiris and Hubbard (1986) would be consistent with this analysis. Zeldes (1986) considers the case wherein individuals are allowed to borrow against the "certain component" of future resources.

${ }^{8}$ See for example Hubbard and Judd (1986).

${ }^{9}$ Recall that the ratio $\mathrm{q} / \mathrm{p}$ is also related to the fraction of the population Iiquidity constrained, which is $(1+(q / p))^{-1}=p /(p+q)$.

10 Empirical studies note at least some sensitivity of consumer spending to temporary tax changes (see Okun, 1971; Blinder and Solow, 1974; Springer, 1975; Juster, 1977; Modigliani and Steinde1, 1977; Blinder, 1981; Poterba and Summers, 1986). Blinder and Deaton (1985) find that the short-run effects of temporary tax changes correspond more closely to those predicted by the permanent-income hypothesis.

${ }^{11}$ The effects of the capital-market imperfection arising from missing markets for insuring against individual-specific fluctuations in earnings have been considered by Barsky, Mankiw, and Zeldes (1986) and by Feldstein (1986). 
Barsky, Mankiw, and Zeldes demonstrate that progressive taxes on future risky income can invalidate Ricardian equivalence and lead to a nonzero marginal propensity to consume out of a debt-financed increase in disposable income. Feldstein makes a more general point -- that nonneutrality under earnings uncertainty need not depend on the existence of non-lump-sum taxes. He shows that, even with lump-sum taxes, inability of agents to forecast precisely their future earnings implies that intergenerational redistribution toward the current generation raises current consumption. As noted also focus on lumpsum taxes in our case against Ricardian equivalence in the presence of borrowing restrictions.

12 Uncertainty over date of death is not the only source of nonneutrality when capital markets are perfect. Weil (1985) shows that within a certain-lifetime model, allowing for population growth invalidates the neutrality of substituting debt for taxes. Generalizing the approaches of Blanchard and Weil, Buiter (1986) finds that if and only if the sum of the population growth rate and the probability of death each period is zero will neutrality hold.

13Hubbard and Judd (1986) compared implied MPCs for both infinite-horizon models (where $p=0$ ) and finite-horizon models under various assumptions about the proportion of the population that is liquidity-constrained. The key finding there was that the significant variation in aggregate MPCs stems primarily from capital-market imperfections, and not from changes in the planning horizon.

${ }^{14}$ In addition, evidence from DeLong and Summers (1986) suggests that liquidity constraints were more important still in the U.S. economy prior to World War II.

${ }^{15}$ As an additional point here, the reduction in marginal tax rates in the current tax reform would reduce the risk-sharing feature of the tax system, stimulating private (precautionary) saving in the Barsky-Mankiw-Zeldes framework. This is inconsistent with the empirical evidence presented in Poterba and Summers (1986).

16 Judd (1986) shows in the context of a perfect-foresight representative-agent model that a substitution of debt for taxes will of ten lead to an antiKeynesian result - the marginal propensity to consume out of the tax cut is negative. The argument is as follows: A tax cut today followed by a future tax increase will increase the welfare cost of taxation, since the future tax increase will depress the future capital stock, whereas the current tax cut cannot increase the current capital stock. This adverse income effect on current consumption accentuates the substitution, or price, effect arising from the lowered cost of future consumption. Hence, both price and income effects act to reduce consumption if taxes are temporarily reduced. 


\section{References}

Auerbach, Alan J. and Kotlikoff, Laurence J. Dynamic Fiscal Policy. Cambridge: Cambridge University Press, 1987.

Barro, Robert J. "Are Government Bonds Net Wealth?" Journal of Political Economy 82 (November-December 1974): 1095-1117.

Barro, Robert J. "Public Debt and Taxes." In Michael J. Boskin, ed., Federal Tax Reform. San Francisco: Institute for Contemporary Studies, $197 \overline{8}$

Barsky, Robert, Mankiw, N. Gregory, and Zeldes, Stephen. "Ricaridan Consumers with Keynesian Properties." American Economic Review 76 (September 1986): 676-691.

Bernanke, Ben S. "Permanent Income, Liquidity, and Expenditure on Automobiles: Evidence from Panel Data." Quarterly Journal of Economics 99 (August 1984): 587-614.

Blanchard, Oliver J. "Debt, Deficits, and Finite Horizons." Journal of Political Economy 93 (April 1985): 223-247.

Blinder, Alan S. and Deaton, Angus. "The Time Series Consumption Function Revisited." Brookings Papers on Economic Activity (2:1985): 465-511.

Blinder, Alan S. and Solow, Robert M. "Analytical Foundations of Fiscal Policy." In Alan S. Blinder, et al. eds., The Economics of Public Finance. Washington, D.C.: Brookings Institution, 1974 .

Boskin, Michael J. and Kotlikoff, Laurence J. "Public Debt and U.S. Saving: A New test of the Neutrality Hypothesis." Working Paper No. 1646, National Bureau of Economic Research, June 1985.

Buiter, Willem H. "Death, Population Growth, Productivity Growth, and Debt Neutrality." Working Paper No. 2027, National Bureau of Economic Research, September 1986.

Calomiris, Charles W. and Hubbard, R. Glenn. "Imperfect Information, Multiple Loan Markets, and Credit Rationing." Mimeograph, Northwestern University, 1986.

DeLong, J. Bradford and Summers, Lawrence H. "The Changing Cyclical Variability of Economic Activity in the United States." In Robert J. Gordon, ed., The American Business Cycle: Continuity and Change. Chicago: University of Chicago Press, 1986.

Diamond, Peter A. "National Debt in a Neoclassical Growth Model." American Economic Review 55 (December 1965): 1126-1150.

Feldstein, Martin. "The Effects of Fiscal Policies When Incomes Are Uncertain: A Contradiction to Ricardian Equivalence." Working Paper No. 2062, National Bureau of Economic Research, November 1986. 
Feldstein, Martin. "Government Deficits and Aggregate Demand." Journal of Monetary Economics 9 (January 1982): 1-20.

Flavin, Marjorie A. "The Adjustment of Consumption to Changing Expectations about Future Income." Journal of Political Economy 89 (October 1981): 974-1009.

Flavin, Marjorie A. "Excess Sensitivity of Consumption to Current Income: Liquidity Constraints or Myopia?" Working Paper No. 1341, National Bureau of Economic Research, May 1984.

Hall, Robert E. and Mishkin, Frederic S. "The Sensitivity of Consumption to Transitory Income: Estimates from Panel Data on Households." Econometrica 50 (March 1982): 461-481.

Hayashi, Fumio. "The Effect of Liquidity Constraints on Consmpution: A CrossSectional Analysis." Quarterly Journal of Economics 100 (February 1985a): $183-206$.

Hayashi, Fumio. "The Permanent Income Hypothesis: Estimation and Testing with Instrumental Variables." Journal of Political Economy 90 (October 1982): 895-916.

Hayashi, Fumio. "Tests for Liquidity Constraints: A Critical Survey." Working Paper No. 1720, National Bureau of Economic Research, October $1985 \mathrm{~b}$.

Hubbard, R. Glenn. "Uncertain Lifetimes, Pensions and Individual Saving." In Zvi Bodie, John Shoven, and David Wise, eds., Issues in Pension

Economics. Chicago: University of Chicago Press, 1986.

Hubbard, R. Glenn and Judd, Kenneth L. "Liquidity Constraints, Fiscal Policy, and Consumption." Brookings Papers on Economic Activity $(1: 1986): 1-50$.

Hubbard, R. Glenn and Judd, Kenneth L. "Social Security and Individual Velfare: Precautionary Saving, Liquidity Constraints, and the Payroll Tax." Working Paper No. 1736, National Bureau of Economic Research, October 1985 .

Hurd, Michael D. and Shoven, John B. "The Distributional Impact of Social Security." Working Paper No. I155, National Bureau of Economic Research, June 1983.

Judd, Kenneth L. "Debt and Distortionary Taxes." Journal of Monetary Economics, forthcoming, 1986.

Juster, F. Thomas. "A Note on Prospective 1977 Tax Cuts and Consumer Spending." Mimeograph, University of Michigan, 1977.

Kotlikoff, Laurence J. "Taxation and Savings: A Neoclassical Perspective." Journal of Economic Literature 22 (December 1984): 1576-1629.

Modigliani, Franco. "Long Run Implications of Alternative Fiscal Policies and the Burden of the National Debt." Economic Journal 71 (December 1961): 730-755. 
Okun, Arthur M. "The Personal Tax Surcharge and Consumer Demand, 1968-70." Brookings Papers on Economic Activity (1:1971): 167-204.

Poterba, James M. and Summers, Lawrence H. "Finite Lifetimes and the Effects of Budget Deficits on National Savings." Working Paper No. 434, Department of Economics, MIT, December 1986.

Runkle, David S. "Liquidity Constraints and the Permanent Income Hypothesis: Evidence for Panel Data." Mimeograph, Brown University, 1984.

Springer, William L. "Did the 1968 Surcharge Really Work?" American Economic Review 65 (September 1975): 644-659.

Tobin, James. Asset Accumulation and Economic Activity. Chicago: University of Chicago Press, 1980 .

Weil, Philippe. Essays on the Valuation of Unbacked Assets. Unpublished Ph.D. dissertation, Harvard University, 1985.

Yaari, Menahem E. "Uncertain Lifetime, Life Insurance, and the Theory of the Consumer." Review of Economic Studies 32 (Apri1 1965): 137-150.

Zeldes, Stephen P. "Consumption and Liquidity Constraints: An Empirical Investigation." Mimeograph, Wharton School, University of Pennsylvania, 1985.

Zeldes, Stephen P. "Optimal Consumption with Stochastic Income: Deviations from Certainty Equivalence." Mimeograph, Wharton School, University of Pennsylvania, 1986. 